\title{
CRENÇAS E ATITUDES LINGUÍSTICAS: O QUE DIZEM OS MARANHENSES SOBRE SUA FALA ${ }^{1}$
}

\author{
Antonio Luiz Alencar Miranda ${ }^{2}$ \\ Valdinete Vieira dos Santos ${ }^{3}$ \\ Frankilson Carvalho da Silva ${ }^{4}$
}

RESUMO: O estudo das crenças e atitudes vem se destacando no cenário da Sociolinguística Variacionista, pois, por meio desses dados, podemos esclarecer fenômenos não explicáveis pelo contexto linguístico e social. Dentro desse conjunto, outro fator é de suma importância para a análise de fatos voltados para a linguagem: as atitudes valorativas que cada falante assume frente à sua fala. Por essas razões, optamos como objeto de estudo as crenças e atitudes dos falantes da cidade de Caxias - MA, com o objetivo de pesquisar as crenças e atitudes linguísticas dos falantes caxienses em relação a sua língua. $O$ corpus do trabalho constitui-se de registros orais coletados, por meio de entrevistas face a face, e que faz parte do projeto Atitudes Linguísticas dos falantes do Maranhão (ALFMA), com os informantes estratificados por sexo, faixa etária e nível de escolaridade. Ao todo, analisamos 36 entrevistas, tendo como base teórica, entre outros, os trabalhos Labov (2008), Tarallo (1990), Lambert \& Lambert (1975), Lambert (1967), Bagno (1999), Miranda (2014). Os resultados da pesquisa apontam para crenças e atitudes positivas em favor da língua falada por maranhenses e indicam os homens, a menor faixa etária e a menor escolaridade como as que avaliam que os maranhenses falam o melhor português.

PALAVRAS-CHAVE: Sociolinguística. Crenças e atitudes. Variação. Mudança.

\section{INTRODUÇÃO}

O presente trabalho tem como objetivo analisar as crenças e atitudes linguísticas dos falantes caxienses em relação a sua língua. Como objetivo específico atestar se os falantes avaliam a própria língua, como a melhor se comparado aos de outros estados. O problema da pesquisa tem como base a ideia de que os falantes têm crenças e atitudes linguísticas acerca do mito da língua falada por maranhense. A hipótese é de que os falantes caxienses avaliam a própria fala como a melhor, em consequência do mito de que o maranhense fala o melhor português do Brasil.

As atitudes linguísticas constituem uma categoria particular, uma vez que o objeto da atitude não são as línguas, mas os grupos que as falam. As atitudes linguísticas representam, assim, um componente fundamental da identidade linguística do falante e possibilitam a compreensão do próprio comportamento

\footnotetext{
1 Pesquisa realizada com o apoio da UEMA/FAPEMA

2 Doutor em Linguística pela Universidade Federal do Rio de Janeiro, UFRJ. Email: antonioluiz_am@hotmail.com

${ }^{3}$ Graduada em Letras/Inglês pelo Centro de Estudos Superiores de Caxias, CESC-UEMA. Email: valdinethvieira@hotmail.com

${ }^{4}$ Graduado em Letras/Inglês pelo Centro de Estudos Superiores de Caxias, CESC-UEMA. Email: frankilson28@gmail.com
} 
linguístico. Nesse sentido, o estudo das crenças e atitudes linguísticas precisa estar fundamentado na relação entre língua e identidade étnica, pois, segundo a definição de Barbosa (2004, p. 30) a atitude como "uma organização duradoura de crenças e cognições em geral, providas de carga afetiva a favor ou contra um objeto social definido.

O texto está dividido da seguinte maneira: apresentação do aporte teórico que assentam as bases da temática em estudo; depois, as orientações metodológicas, corpus e instrumento da pesquisa; em seguida, as análises e interpretações dos resultados e, por fim, as conclusões com a comprovação ou refutação da hipótese proposta e o cumprimento dos objetivos levantados.

\section{CRENÇAS E ATITUDES LINGUÍSTICAS}

É com Lambert et. al. (1960), na década de 60, que os estudos sobre atitudes linguísticas ganham ênfase e sistematização na avaliação dos falantes, ao refletir sobre as atitudes subjacentes dos ouvintes. Lambert e Lambert (1975, p. 100) entendem a atitude como "uma maneira organizada e coerente de pensar, sentir e reagir em relação a pessoas, grupos, problemas sociais ou, de modo mais geral, a qualquer acontecimento no ambiente". Nessa mesma visão, Sarnoff (1970, p. 279) assinala que as atitudes em geral são "uma disposição para reagir favorável ou desfavoravelmente a uma classe de objetos".

Lambert (1967) entende que a atitude se constitui de três componentes colocados no mesmo nível: o componente cognoscitivo, de saber ou crença implicando convicções sobre o mundo; o componente afetivo, de valoração alicerçada em juízos de valor e de sentimentos relativos acerca do objeto; e o componente comportamental, de conduta ou predisposição comportamental propriamente dita.

$\mathrm{Na}$ mesma linha de pensamento, Schneider (2007, p. 78) conceitua atitudes linguísticas "qualquer indicador cognitivo, afetivo ou comportamental de reações avaliativas em direção aos traços de fala, às variedades linguísticas e aos seus falantes" e que "as atitudes linguísticas refletem as nossas crenças culturalmente motivadas e condicionadas ao sistema de valores acordados pelos membros da sociedade e/ou grupos sociais" (op. cit.). 
As atitudes linguísticas relacionam-se intimamente com as avaliações de um falante sobre determinada língua. Para se compreender as atitudes linguísticas, é preciso incorporar o estudo de crenças, sendo que esta é entendida como uma forma de pensamento, uma maneira subjetiva da realidade que implica experiências resultantes de processos sociais. Barbosa, ao relacionar crença e atitude, relata que a crença seria "uma opinião de certeza e a atitude uma manifestação dela, mas que ambos os termos estão inter-relacionados" (BARBOSA, 2004, p. 38).

$\mathrm{Na}$ visão de Richards e Schmidt (2002), as crenças, no âmbito da Linguística, estão relacionadas às ideias que os falantes têm sobre os mais diferentes aspectos de uma língua e que podem influenciar suas atitudes em relação a ela. Também definem as atitudes linguísticas como "as atitudes que os falantes de diferentes línguas ou variedades linguísticas têm no que concerne às línguas faladas por outras comunidades idiomáticas ou à sua própria língua".

Labov $(2008$, p. 197, 201) estudou as atitudes linguísticas na comunidade da Ilha Martha's Vineyard, na costa de Massachusetts, Estados Unidos da América. $O$ estudioso investigou as diferenças na altura do primeiro elemento dos ditongos/aw/, em palavras como out, house, e /ay/, em palavras como white, wine, para analisar se essas variáveis seriam apenas sociais ou se apontariam para a estruturação do grupo social. Ele percebeu que a diferenciação linguística se dava entre membros da população que pretendiam permanecer na ilha e outros que desejavam dela sair a procura de emprego no continente.

Labov (2008, p. 58), ao avaliar as entrevistas, conclui que o significado da altura do primeiro elemento dos ditongos /aw/, a julgar pelo contexto em que ocorre, é uma atitude positiva em relação à comunidade. Isso permitiu ao linguista classificar a atitude em três categorias: positiva, quando exprime sentimentos positivos acerca do objeto; negativa, quando manifesta sentimentos negativos em relação ao objeto; e, neutra, quando não expressa sentimento nem positivo nem negativo acerca do objeto.

Dessa forma, entendemos que qualquer indivíduo é capaz de perceber diferentes formas no tocante ao uso da língua e, por essa razão, terá comportamentos linguísticos que aprovam ou desaprovam a própria fala e a fala 
dos outros. Por isso, partindo dessa percepção, investigamos as crenças e as atitudes linguísticas dos falantes da cidade de Caxias.

\section{METODOLOGIA}

Tomamos como base os princípios teóricos e metodológicos da Sociolinguística Variacionista (LABOV, 1966, 2008), e os estudos de crenças e atitudes linguísticas (LAMBERT, 1967) mediante aos parâmetros (cognoscitivo, afetivo e conativo) para procedimentos de análise.

A pesquisa de campo foi realizada por meio de entrevistas face a face com o auxílio do gravador de áudio, utilizando um questionário contendo 22 perguntas-guias. As perguntas das entrevistas permitem flexibilidade nas respostas, porque são orientadoras, possuem temas livres e tópicos não previstos pelo entrevistador. Em seus trabalhos Labov (2008) recomenda a entrevista, como um modelo tradicional de coleta, em que o pesquisador tem de minimizar os efeitos negativos, de sua presença, na fala dos entrevistados, a esse fenômeno Labov chamou de paradoxo do observador. O objetivo é colher dados da fala espontânea, que normalmente ocorre quando o falante não está sendo observado.

O corpus deste trabalho é um recorte de 36 entrevistas, entre as 162 realizadas pelo coordenador Antônio Luiz Alencar Miranda, os bolsistas de iniciação científica e os auxiliares de pesquisa, que fazem parte do projeto Atitudes linguísticas dos falantes do Maranhão - ALFMA, do Centro de Estudos Superiores de Caxias - CESC, da Universidade Estadual do Maranhão - UEMA. Todos os informantes são residentes na cidade de Caxias, região leste do Maranhão. Desses 36 informantes, vinte e quatro são naturais de Caxias, quatro de Codó, cinco são piauienses, e três do interior do Maranhão, nascidos ou que tenha vindo morar em Caxias até os sete anos de idade, estratificados pelas variáveis sociais de sexo (masculino e feminino), escolaridade (do analfabeto aos nove anos de escolaridade e Dez anos de escolaridade em diante) e, faixa etária (18 a 35,36 a 49 e 50 a 65 anos em diante).

Entre as 22 questões-guias, para este trabalho, selecionamos apenas as respostas de três questões, que as relacionaremos com as variáveis sociais de sexo, faixa etária e escolaridade: a primeira, Quando você percebe que alguém 
falou alguma palavra errada, o que você faz diante disso? A palavra errada, neste estudo, tem o sentido de não seguir os cânones da gramatica normativa, nesse aspecto, esperávamos que os informantes avaliassem a fala do outro, manifestando crenças e atitudes positivas ou negativas; a segunda, Em sua opinião o Maranhão é o estado que fala o melhor português? A proposta não é saber qual o estado fala o melhor português, mas saber as crenças e atitudes dos informantes, se é no estado do Maranhão que se fala o melhor português, como diz o mito. Sabemos que para a Sociolinguística não há a melhor ou a pior, toda língua é adequada à sua comunidade de fala; a terceira, $O$ português que você fala é melhor do que o falado por seus pais? A expectativa é receber respostas com crenças e atitudes, que avaliassem a fala dos pais relacionada com o português mais elaborado, dentro dos padrões da gramática normativa.

\section{ANÁLISE E DISCUSSÃO DOS RESULTADOS}

Neste trabalho, apresentaremos a análise de apenas três questões, cruzando-as com as variáveis sociais sexo, faixa etária e escolaridade. Os dados para análise foram às respostas dadas pelos informantes nas entrevistas que fazem parte do projeto ALFMA (2016), já que tais respostas contêm os discursos dos informantes pesquisados a respeito da língua falada. As respostas fornecidas pelos informantes converteram-se em tabelas para a análise.

Crenças e atitudes linguísticas pelo sexo.

Tabela 1 - Atitude/crenças dos informantes pelo sexo, em relação à pergunta: Quando você percebe que alguém falou alguma palavra errada, o que você faz diante disso?

\begin{tabular}{lcccc}
\hline $\begin{array}{l}\text { Sexo } \\
\text { Avaliação }\end{array}$ & Masculino & Feminino \\
& & & Aplic/total & $\%$ \\
\cline { 2 - 5 } & Aplic/total & $\%$ & $6 / 18$ & 33 \\
\hline Positiva & $9 / 18$ & 50 & $12 / 18$ & 67 \\
Negativa & $9 / 18$ & 50 & $18 / 36$ & 100 \\
\hline Total & $18 / 36$ & 100 &
\end{tabular}

Fonte: Projeto ALFMA, 2016.

Na questão: Quando você percebe que alguém falou alguma palavra errada, o que você faz diante disso? Quanto ao posicionamento positivo, os homens alcançaram um percentual de $50 \%$. Já as mulheres resultaram apenas em 33\%. Quanto ao posicionamento negativo em relação aos homens manteve o 
mesmo percentual. Já as mulheres $67 \%$ demonstrando atitude negativa. Nesta questão não houve registro de atitudes neutras.

Essa análise está apoiada no depoimento do informante 33, que assim se expressou:

Eu convido a pessoa, eu convido e faço a retificação, eu já fiz e num foi só uma vez, a gente fica inquietado, eu digo nós temos que ensinar o povo, até no trânsito, até no dia a dia, na questão de postura e compostura.

Em sua fala, há uma crença de que há uma língua correta manifestada por uma atitude presente pelo componente conativo. O informante tem consciência das noções de certo e errado conforme a gramática normativa, sendo resultado, principalmente, do processo de escolarização.

Tabela 2 - Atitude/crenças dos informantes pelo sexo, em relação à pergunta: Em sua opinião $o$

\begin{tabular}{lcccc}
\multicolumn{5}{c}{ Maranhão é o estado que fala o melhor português? } \\
Sexo & Masculino & & Feminino \\
& & & & \\
\cline { 2 - 5 } & Aplic/total & $\%$ & Aplic/total & $\%$ \\
\hline Positiva & $9 / 18$ & 50 & $6 / 18$ & 33 \\
Negativa & $5 / 18$ & 28 & $7 / 18$ & 39 \\
Neutra & $4 / 18$ & 22 & $5 / 18$ & 28 \\
\hline Total & $18 / 36$ & 100 & $18 / 36$ & 100 \\
\hline
\end{tabular}

Fonte: Projeto ALFMA, 2016.

Em relação à pergunta: Em sua opinião o Maranhão é o Estado que fala 0 melhor português? Quanto ao posicionamento positivo, os dados mostram que $50 \%$ dos homens avaliaram que o Maranhão fala o melhor português, e em relação às mulheres 33\% atribuindo atitude positiva. Quanto ao posicionamento negativo $28 \%$ dos homens tiveram atitude negativa e as mulheres $39 \%$ tiveram atitude negativa. Quanto ao posicionamento neutro $22 \%$ dos homens não responderam, as mulheres $28 \%$. O gráfico permite concluir que os homens têm uma avaliação positiva da fala em relação às mulheres. Verificamos alguns casos que merecem destaque. $O$ primeiro deles diz respeito à prevalência do componente cognoscitivo, quando manifesta seus conhecimentos acerca da própria fala em relação a outros estados do Brasil e consciência interdialetal quando avalia sua fala pela fala de outro estado. Assim declarou o informante 34: 
Rapaz, a vista de outros, de outros estados aí, o maranhense fala melhor em primeiro lugar, o português mais correto.

O seu depoimento é sustentado por meio da crença de um falar "mais certo" dentre os outros falares.

Outra resposta foi do informante 09, alicerçada no componente cognoscitivo, associado ao afetivo. Essa postura de rejeição ao que é diferente ou regional leva, com certeza, à inclusão do componente conativo:

\begin{abstract}
É. Porque o pior estado é o Piauí. A Bahia eu tinha uma amiga eu morei em São Paulo em 76 e 77, 78 e 79 morei em São Paulo e vim me embora. E uma amiga trabalhava comigo e ela falava desse jeito "hoje nois vai naquela lanchionete? E eu dizia assim "hoje nós não vai aquela lanchionete" "nós vamos em outra lanchionete" e o pessoal do Piauí o Greicivan fala errado meu Deus do céu! Mas eu falei pra não repreender ele: "pro mode de que D. Dione que você num vai pra Teresina, hoje? Que era pra a gente ido pra Teresina hoje" aí eu digo pra ele: "olha porque não deu, mas amanhã nós vamos, tá bom". O piauiense fala erradíssimo! Mas vocês não são do Piauí, não?
\end{abstract}

De acordo com os depoimentos os informantes demonstram segurança linguística sobre a sua fala, considerando-a mais prestigiada pela qual julgam e negativizam as falas dos demais estados. As respostas a essa pergunta evidenciam que a atitude afetiva comum à maioria dos informantes é em defesa da língua nativa, demonstrando solidariedade linguística.

Tabela 3 - Atitude/crenças dos informantes pelo sexo, em relação à pergunta: O português que você fala é o melhor falado por seus pais?

\begin{tabular}{lcccc}
\hline Sexo & Masculino & & Feminino & \\
\cline { 2 - 5 } & Aplic/total & $\%$ & Aplic/total & $\%$ \\
\hline Positiva & $11 / 18$ & 61 & $11 / 18$ & 61 \\
Negativa & $4 / 18$ & 22 & $1 / 18$ & 6 \\
Neutra & $3 / 18$ & 17 & $6 / 18$ & 33 \\
\hline Total & $18 / 36$ & 100 & $18 / 36$ & 100 \\
\hline
\end{tabular}

Fonte: Projeto ALFMA, 2016.

Para a pergunta: $O$ português que você fala é o melhor falado por seus pais? Em resposta, tanto os homens quanto às mulheres responderam 'sim'(equivalendo atitude positiva) em $61 \%$ dos informantes do mesmo sexo, expresso na tabela 3. Quanto às atitudes negativas, informantes de ambos os sexos, conforme os dados, foi baixa com $22 \%$ para os homens, $6 \%$ para as mulheres e a atitude neutra com $17 \%$, para os homens e $33 \%$, para as mulheres. 
Nas respostas, há aqueles que percebem mudanças diacrônicas em relação à gradação etária na fala de informantes de mais idade, quando destacam em referência aos jovens, como agentes inovadores, principalmente, pelo uso insistente de gírias que, em geral, os falantes mais conservadores reprovam. Esse fato pode ser exemplificado no depoimento do informante 24:

\begin{abstract}
Acho que tenho muito que aprender com eles, é por causa da, da juventude de hoje que a gente acaba pegando assim umas palavras que num tem nada a ver, e é sempre bom tá perto deles que a gente aprende a falar melhor
\end{abstract}

A informante acredita que as formas de falar de pessoas de gerações anteriores é que devem ser seguidas e não se adequar a linguagem dos jovens.

\title{
CRENÇAS E ATITUDES POR FAIXA ETÁRIA
}

A faixa etária é um dos fatores que pode revelar mudança, e as duas formas de estudar a mudança linguística são através do tempo aparente e em tempo real. O estudo em tempo aparente se refere à observação de falantes de diferentes faixas etárias em um recorte sincrônico, enquanto que a de tempo real estuda, por exemplo, os mesmos falantes em épocas diferentes.

Tabela 4 - Atitude/crenças dos informantes por faixa etária, em relação à pergunta: Quando você percebe que alguém falou alguma palavra errada, o que você faz diante disso?

\begin{tabular}{|c|c|c|c|c|c|c|}
\hline \multirow{2}{*}{$\begin{array}{l}\text { Faixa etária } \\
\text { Avaliação }\end{array}$} & \multicolumn{2}{|l|}{$1^{\mathrm{a}}$} & $2^{\underline{a}}$ & \multicolumn{3}{|c|}{$3^{\mathrm{a}}$} \\
\hline & Aplic/total & $\%$ & Aplic/total & $\%$ & Aplic/total & $\%$ \\
\hline Positiva & $6 / 12$ & 50 & $5 / 12$ & 42 & $4 / 12$ & 33 \\
\hline Negativa & $6 / 12$ & 50 & $7 / 12$ & 58 & $8 / 12$ & 67 \\
\hline Total & $12 / 36$ & 100 & $12 / 36$ & 100 & $12 / 36$ & 100 \\
\hline
\end{tabular}

Fonte: Projeto ALFMA, 2016.

Em relação à faixa etária dos falantes, quando perguntamos: Quando você percebe que alguém falou alguma palavra errada, o que você faz diante disso?". O gráfico acima mostra que os informantes da 1 a faixa etária demonstraram tanto atitudes positivas quanto atitudes negativas, ou seja, um percentual de $50 \%$ para cada atitude. Já os informantes da $2^{2}$, com $42 \%$, tiveram atitude positivas e $58 \%$ atitudes negativas e a $3^{\text {a }}$ faixa etária $33 \%$ tiveram atitude positivas e $67 \%$, respectivamente, obtiveram atitudes negativas. 
Estes resultados apontam duas possíveis interpretações, a primeira é que os informantes da $1^{\underline{a}}$ faixa, ou seja, os mais jovens corrigem e buscam aperfeiçoar a maneira de falar mais do que os informantes de mais idade, pois de acordo com os dados, a $2^{\mathrm{a}}$ e $3^{\mathrm{a}}$ faixas etárias, de certa forma, desfavorecem a correção ao uso da língua, havendo um comportamento diferenciado em relação às outras faixas etárias. A segunda é que os informantes da $3^{\text {a }}$ faixa etária são responsáveis por $67 \%$ das indicações negativas, demonstrando solidariedade linguística às formas erradas empregada na fala, inconscientemente, revelam que embora algumas palavras sejam usadas de forma errada, entendem que esse fenômeno atende as necessidades contidas no contexto linguístico e governada por forças naturais. Informante 25 , da $3^{\underline{a}}$ faixa etária, fala:

Não, eu não gosto, eu nem corrijo quem fala assim, falou errado fez colocação errada, eu prefiro ficar na minha.

Esse grupo etário revelou resignação às variantes estigmatizadas da fala e tem consciência quando o "erro" acontece.

Tabela 5 - Atitude/crenças dos informantes por faixa etária, em relação à pergunta: $E m$ sua opinião o Maranhão é o estado que fala o melhor português?

\begin{tabular}{|c|c|c|c|c|c|c|}
\hline \multirow{2}{*}{$\begin{array}{l}\text { Faixa etária } \\
\text { Avaliação }\end{array}$} & \multicolumn{2}{|l|}{$1 \underline{a}$} & \multicolumn{2}{|l|}{$2^{a}$} & \multicolumn{2}{|l|}{$3^{\underline{a}}$} \\
\hline & Aplic/total & $\%$ & Aplic/total & $\%$ & Aplic/total & $\%$ \\
\hline Positiva & $6 / 12$ & 50 & $5 / 12$ & 42 & $4 / 12$ & 33 \\
\hline Negativa & $6 / 12$ & 50 & $3 / 12$ & 25 & $3 / 12$ & 25 \\
\hline Neutra & ----- & ---- & $4 / 12$ & 33 & $5 / 12$ & 42 \\
\hline Total & $12 / 36$ & 100 & $12 / 36$ & 100 & $12 / 36$ & 100 \\
\hline
\end{tabular}

Fonte: Projeto ALFMA, 2016.

Em relação à pergunta: "Em sua opinião o Maranhão é o estado que fala o melhor português?" Essa pergunta propala o mito do português maranhense ser melhor falado em relação ao português dos demais estados brasileiros, o que nas palavras de Bagno (1999) não passa de uma "grande bobagem", por não ter uma sustentação científica.

Quanto aos resultados, novamente houve um equilíbrio percentual, com os informantes da $1^{\underline{a}}$ faixa etária, tendo em vista que eles avaliaram positivamente e negativamente com o percentual de $50 \%$. Os informantes da $2^{2}$ faixa etária, 42 $\%$ avaliaram positivamente, $25 \%$ avaliaram negativamente e $33 \%$ não opinaram. 
Os informantes da terceira faixa etária 33\% avaliaram positivamente, $25 \%$ avaliaram negativamente e $42 \%$ não opinaram, ou seja, se mantiveram neutro. Segundo o informante 24:

Menina eu já vi muitas pessoas falar bem pra caramba, então eu acho que o maranhense assim, eu já estive alguns anos em Brasília e eles elogiam muito os maranhenses, porque diz que o maranhense fala bem, se você for se colocar diante de outros, de outras capitais você vai ver que o Maranhão tá sim em primeiro lugar, é tão tal que o paulista se acha, mas o paulista fala errado pra caramba, eu acho que a gente está em primeiro lugar sim. Concordo.

O componente cognoscitivo, de crença, presente na atitude linguística manifestada no depoimento acima, associa-se ao componente afetivo e ao mesmo tempo utiliza o componente conativo quando estigmatiza outros falares.

Os resultados, de Miranda (2014), mostram que os falantes avaliam positivamente a fala maranhense como a melhor do país, com percentuais de $60 \%$ referente à primeira faixa etária, taxa de $70 \%$ para a segunda e percentagem de $66,7 \%$ para a terceira. É importante ressaltar que, em todas as idades os percentuais ultrapassam $60 \%$, indícios fortes de crenças e de atitudes, motivo pelo qual sustenta ainda hoje o imaginário sobre a fala local.

Tabela 6 - Atitude/crenças dos informantes por faixa etária, em relação à pergunta: O português que você fala é melhor do que o falado por seus pais?

\begin{tabular}{lcccccc}
\hline $\begin{array}{l}\text { Faixa etária } \\
\text { Avaliação }\end{array}$ & \multicolumn{1}{c}{$1^{\underline{a}}$} & \multicolumn{3}{c}{$2^{\underline{a}}$} & $3^{\text {a }}$ & \\
\cline { 2 - 7 } & Aplic/total & $\%$ & Aplic/total & $\%$ & Aplic/total & $\%$ \\
\hline Positiva & $8 / 12$ & 67 & $8 / 12$ & 67 & $9 / 12$ & 72 \\
Negativa & $4 / 12$ & 33 & $4 / 12$ & 33 & $3 / 12$ & 28 \\
\hline Total & $12 / 36$ & 100 & $12 / 36$ & 100 & $12 / 36$ & 100 \\
\hline
\end{tabular}

Fonte: Projeto ALFMA, 2016.

Quanto à pergunta: O português que você fala é o melhor do que o falado por seus pais? As respostas a essa pergunta evidenciam que a atitude positiva prevaleceu em todas as faixas etárias. $\mathrm{Na} 1^{\underline{a}} 67 \%$, na $2^{\underline{a}} 67 \%$, e na $3^{\underline{a}} 72 \%$. Já para avaliação negativa as percentagens são $33 \%$ para a $1^{\underline{a}}$ e $2^{\underline{a}}$ e $28 \%$ para a $3^{\underline{a}}$ faixa etária. Os informantes, que reagiram positivamente, fazem referência ao nível de escolaridade como indicador de mudança para o melhor português. Está aí uma clara alusão à influência direta da escola na mudança da fala, salientando 
as diferenças, entre a fala dos mais velhos e a dos jovens, como agentes de mudança. Esse fato pode ser exemplificado com a seguinte fala do informante 21 :

Acredito que sim até porque as oportunidades de leitura foram maiores, foram melhores também, é como eu lhe disse anterior a minha mãe fez só até o quarto ano, naquela época que se estudava até o quinto e meu pai ele foi analfabeto até a gente aprender ler e escrever e ensinar ele escrever o nome dele e é por isso que eu acredito que eu deva falar melhor que eles.

Todos os informantes disseram que falam melhor que os seus pais, porque tiveram a oportunidade de estudar. Martins (2010), quando realizou um estudo com os usos dos pronomes tu/você/senhor no Estado do Amazonas, trabalho que originou sua dissertação intitulada $A$ Alternância do tu/você/senhor no Município de Tefé - Estado do Amazonas, cita Labov (1994 p. 46) para explicar que a mudança linguística pode estar vinculada com a faixa etária:

[...] essas diferenças, entre falantes da faixa etárias mais jovens com as demais faixas etárias, pode sinalizar alguma possível mudança nas formas de referências, entrando na comunidade como reflexo de mudanças estruturais na sociedade, mas não estamos descartando a possibilidade de as eventuais diferenças serem apenas relativas às diferenças de faixa etária que se repetem a cada geração, sem revelarem necessariamente mudança em progresso. (MARTINS, 2010, p. 59)

Foi possível visualizar na tabela 6 , que todas as faixas etárias têm uma grande diferença percentual entre as atitudes positivas, negativas e neutras. A que mais se destaca é a atitude positiva. A explicação para esse fenômeno tem que se levar em conta, a faixa etária dos informantes de acordo com o português falado, atualmente em referência à fala dos seus pais. Como mostraram os resultados, embora os jovens façam uso das variantes mais inovadoras, a primeira faixa etária é a que não faz muita diferença na escala, entre as atitudes positiva e negativa. Então, isso se explica pelo fato de os pais dos informantes de 1a faixa etária serem mais jovens que os pais dos informantes da $2^{\underline{a}}$ e $3^{\underline{a}}$ faixas.

\section{ATITUDE POR ESCOLARIDADE}

O fator escolaridade é uma variável importante em trabalhos variacionista, porque cada nível pode revelar características, de acordo com a norma linguística, valorizadas por indivíduos que possuem um maior status de escolaridade, referente ao que apresente expressões mais prestigiadas. 
Tabela 7 - Atitude/crenças dos informantes pela escolaridade, em relação à pergunta: $O$ português que você fala é melhor do que o falado pelos seus pais?

\begin{tabular}{ccccc}
\hline Escolarização & \multicolumn{2}{c}{$\begin{array}{c}\text { Analfabeto ao } \\
\text { Fund. maior }\end{array}$} & \multicolumn{2}{c}{$\begin{array}{c}\text { Ens. Médio } \\
\text { Em diante }\end{array}$} \\
\cline { 2 - 5 } Avaliação & Aplic/tot & $\%$ & Aplic/tot & $\%$ \\
\hline Positiva & $3 / 18$ & 17 & $12 / 18$ & 67 \\
Negativa & $15 / 18$ & 83 & $6 / 18$ & 33 \\
\hline Total & $18 / 36$ & 100 & $18 / 36$ & 100 \\
\hline
\end{tabular}

Fonte: Projeto ALFMA, 2016.

A pergunta inquirida foi: Quando você percebe que alguém falou alguma palavra errada, o que você faz diante disso? Os informantes com até 9 anos de escolaridade manifestaram em $17 \%$ com atitudes positivas e um efeito maior em atitudes negativas, representando $83 \%$. Já os informantes da escolaridade com mais de dez anos tiveram $67 \%$, com atitudes positivas, contra $33 \%$ de atitudes negativas.

A sensibilidade linguística é uma atitude caracterizada pelo o grau de consciência do falante em relação à diversidade linguística e de sua atitude em relação à essa diversidade. A variável escolaridade apresentou grau de sensibilidade linguística, sendo que os de maior escolaridade demonstraram uma maior conscientização em relação às características da linguagem. A informante 18 relata:

Às vezes em sala de aula eu corrijo meus alunos né, procuro sempre tá
falando a palavra corretamente pra que eles vejam a diferença do que
eles falam e a forma que eu digo a forma correta e a forma errada, se for
alguém que eu não tenho intimidade e não for na sala de aula eu não
tenho como fazer isso. De certa forma sim, pelo menos nos meus
pensamentos, mentalmente eu digo rasgou a gramática. [...]
Principalmente os erros de concordância, meu Deus! Como é que as
pessoas conseguem.

O informante acima favorece a correção, acredita que a forma correta de falar é a ensinada pela gramática. E estigmatiza a forma não padrão discernindo as noções de "certo" e "errado" quanto aos usos da língua. Há intolerância e atitude desfavorável quando se depara diante da palavra inadequada, da concordância verbal não realizada.

No entanto, encarar a língua como um sistema homogêneo e invariável significa negar a sua própria natureza heterogênea, já que a heterogeneidade é um princípio inerente a ela. 
Tabela 8 - Atitude/crenças dos informantes pela escolaridade, em relação à pergunta: Em sua opinião o Maranhão é o Estado que fala o melhor português?

\begin{tabular}{ccccc}
\hline Escolarização & \multicolumn{2}{c}{$\begin{array}{c}\text { Analfabeto ao } \\
\text { Fund. maior }\end{array}$} & \multicolumn{2}{c}{$\begin{array}{c}\text { Ens. Médio } \\
\text { Em diante }\end{array}$} \\
\cline { 2 - 5 } Avaliação & Aplic/tot & $\%$ & Aplic/tot & $\%$ \\
\hline Positiva & $9 / 18$ & 50 & $6 / 18$ & 33 \\
Negativa & $9 / 18$ & 50 & $12 / 18$ & 67 \\
\hline Total & $18 / 36$ & 100 & $18 / 36$ & 100
\end{tabular}

Fonte: Projeto ALFMA, 2016.

Quanto à questão: Em sua opinião o Maranhão é o Estado que fala $o$ melhor português? De acordo com o gráfico acima, os informantes da escolaridade menor reagiram mais positivamente, com $50 \%$ do que os informantes da escolaridade maior, com $33 \%$ de atitude positiva e os que despertaram uma reação negativa em números, constam de $50 \%$, para a menor escolarização e $67 \%$, para a maior. Assim, demonstraram consciência de que não existe uma forma de falar mais prestigiada.

Sim porque é a melhor, é a melhor do Brasil é a língua que fala melhor são os maranhenses já morei em São Paulo e Pará porque também ele não fala palavra completa só fala pela metade 'ocê' (Informante de Caxias, F19).

O informante afirma que a língua melhor falada é do Maranhão. Sua atitude é cognoscitiva por avaliar positivamente a própria fala, e conativa por construir o estereótipo de que os estados de São Paulo e Pará falam pela metade, exemplificando com a variante pronominal estigmatizada o 'ocê'. Em consonância com tal opinião está o informante 27 , que reforça tal questão:

Sim até porque por eu ter andado né? Acho que quase os 27 estado do Brasil né? Por onde eu andei todos os lugares que eu andei e principalmente aqui aonde nós vive aqui em Caxias né? Aqui essa região nossa aqui é um dos Português mais claro, mais simples, de qualquer pessoa entender no mundo, essa região nossa aqui é um dos melhores, num é porque eu seja filho daqui, more aqui, mas por onde eu já andei é um dos lugar que o Português é mais claro e mais simples pra qualquer ser humano entender, é essa região nossa aqui (Informante de Caxias, M29).

Nas falas, percebemos que atitude perante a língua é cognoscitiva, por mencionar que conhece as formas de falar de outros Estados. A outra atitude é a afetiva e lealdade linguística, por defenderem e acreditarem que quem fala melhor são os maranhenses e, por afirmarem, que fala um português bem claro, simples e correto. 
De acordo com Tarallo (1990) [...] "em uma sociedade tão estratificada como a nossa, fatal será que o nível socioeconômico e de escolaridade do indivíduo tenha direta relevância sobre seu desempenho linguístico". Estes dados evidenciam a interferência da escola, levando os falantes com maior número de anos de escolarização a erradicar na ideologia de uma melhor língua, pela comunidade a qual pertence.

\begin{tabular}{|c|c|c|c|c|}
\hline \multirow{2}{*}{$\begin{array}{c}\text { Escolarização } \\
\text { Avaliação }\end{array}$} & \multicolumn{2}{|c|}{$\begin{array}{l}\text { Analfabeto ao } \\
\text { Fund. maior }\end{array}$} & \multicolumn{2}{|c|}{$\begin{array}{l}\text { Ens. Médio } \\
\text { Em diante }\end{array}$} \\
\hline & Aplic/tot & $\%$ & Aplic/tot & $\%$ \\
\hline Positiva & $9 / 18$ & 50 & $12 / 18$ & 67 \\
\hline Negativa & 9/18 & 50 & $6 / 18$ & 33 \\
\hline Total & $18 / 36$ & 100 & $18 / 36$ & 100 \\
\hline
\end{tabular}

Fonte: Projeto ALFMA, 2016.

O resultado da questão: $O$ português que você fala é melhor do que $O$ falado por seus pais? Foi muito significativo em relação à escolaridade, quanto à avaliação positiva dos informantes. Os informantes da escolaridade menor com $50 \%$ de atitude positiva e a escolaridade maior com $67 \%$. A escolaridade maior reagiu positivamente demonstrando uma maior conscientização em relação a sua maneira de falar, comparando a dos seus pais. Reconhecem e conseguem associar o modo de falar ao um bom desempenho linguístico. No entanto, associam também o modo de falar a características físicas articulatórias da fala, tais como: entonação, emprego correto das palavras, pronúncia, concordância, regência. Vejamos no depoimento do informante 27:

É, é porque é mais explicativo né, é mais correto né e aquele tempo deles né? As coisa era mais puxada né, as palavra era mais né, hoje simplificou muito as coisa, então hoje muita coisa que eles falava de uma maneira... Hoje simplificou, mudou bastante.

Concluímos que os informantes mais escolarizados tendem a se preocupar mais com a forma de falar. Ambos percebem mudanças diacrônicas em aspectos metafórico-emocionais na fala, assim é nítida a consciência global em apontar aspectos de variação intradialetal.

Os entrevistados que apresentaram uma maior atitude nesse quesito foram os universitários, independente de sexo e faixa etária. Por isso, foi possível 
constatar que é forte a influência do fator escolaridade no desempenho da avalição do falante.

\section{CONCLUSÃO}

O intuito deste trabalho foi analisar as crenças e atitudes linguísticas dos falantes caxienses em relação a sua língua. Mais especificamente, atestar se os falantes avaliam a própria língua, como a melhor se comparado aos de outros estados. Podemos dizer que os objetivos foram alcançados, pois conseguimos avaliar as respostas dos 36 informantes, enfocando três questões consideradas importantes para o estudo.

Observamos que as avaliações positivas só aconteceram com maiores percentagens para as respostas à pergunta: $O$ português que você fala é $o$ melhor falado por seus pais? Quanto à variável sexo, nas duas variantes os informantes avaliam com $61 \%$ a própria fala como a melhor. Quanto à faixa etária, todas as faixas etárias avaliaram positivamente com $67 \%$ para a primeira e segunda e $72 \%$ para a terceira. Quanto à escolaridade, somente o ensino médio em diante avaliou positivamente com $67 \%$ a própria fala.

As respostas para relação à pergunta: Em sua opinião o Maranhão é o Estado que fala o melhor português? Quanto à variável sexo, na variante masculina 50\%, contra 33\% para a feminina como positiva. Quanto à faixa etária, avaliaram $50 \%$ para a primeira, $42 \%$ para a segunda e $33 \%$ para a terceira. Quanto à escolaridade, sem escolarização ao fundamental maior avaliou com $50 \%$, enquanto o ensino médio em diante avaliou positivamente com $33 \%$ a própria fala.

Como observamos, a variante ensino médio em diante foi a favorecedora do melhor português, como mostram as tabelas 7 e 9 . No entanto, apresenta pequenos índices na tabela 8 . Esses resultados mostram que os informantes manifestam o mito entre os falantes, de que o melhor português do Brasil é o falado no Maranhão, embora os percentuais não sejam significativos como esperávamos em nossa hipótese.

Concluímos que, no corpus investigado, não há como sustentar o mito de que o maranhense fala o melhor português, com base nos índices apresentados nas análises do trabalho em foco. 
Por meio das atitudes e crenças, verificamos que na fala dos informantes circula uma visão do senso comum, marcado por atitudes avaliativas sustentadas por estereótipos linguísticos, principalmente, em relação à própria língua, ou seja, noções de variação da língua como, por exemplo, diferenças geográficas, em se tratando da análise de atitudes linguísticas. Em suma, as opiniões foram satisfatórias e relevantes, uma vez que a mudança se percebe por meio de avaliações e é, nesse sentido, que os informantes manifestam suas crenças e atitudes.

\section{BELIEFS AND LINGUISTIC ATTITUDES: WHAT THE MARANHENSES SAY ABOUT YOUR TALKING}

ABSTRACT: The study of beliefs and attitudes has been highlighted in the scene of Variationist Sociolinguistics, because, through these data, we can clarify phenomena that cannot be explained by the linguistic and social context. Within this set, another factor is of paramount importance for the analysis of facts directed to the language: the valuing attitudes that each speaker assumes in front of his speech. For these reasons, we chose as object of study the beliefs and attitudes of the speakers of the city of Caxias-MA, with the objectives of researching the linguistic beliefs and attitudes of the caxienses speakers in relation to their language. The corpus of the work consists of oral records collected through face-to-face interviews, which is part of the project Linguistic Attitudes of speakers of Maranhão (ALFMA), with the informants stratified by sex, the age group and level of education. In all, we analyzed 36 interviews, with theoretical basis, among others, the works Labov (2008), Tarallo (1990), Lambert \& Lambert (1967), Bagno (1999), Miranda (2014). The results of the research point to positive beliefs and attitudes in favor of the language spoken by maranhenses and indicate men, the lower age group and the lower level of schooling, such as those that evaluate that the people of Maranhão speak the best Portuguese.

KEYWORDS: Sociolinguistics. Beliefs and attitudes. Variation. Change.

\section{REFERÊNCIAS}

BAGNO, Marcos. Preconceito linguístico: o que é como se faz. 17 ed. São Paulo: Loyola, 2002.

BARBOSA, Gabriela de Campos. Atitudes linguísticas e identidade na fronteira Brasil-Colômbia. 141 f. 2004. Tese (Doutorado em Linguística): Faculdade de Letras/UFRJ, Rio de Janeiro, 2004.

GUEDELHA, Carlos Magalhães. Crenças e atitudes: um estudo dialetológico. Juiz de Fora, disponível em: http://www.uff..br/revistagatilho/files/2011/10/guedelha.pdf. Acesso em: 14 set. 2012.

LABOV, Wiliam. Padrões sociolinguísticos. São Paulo: Parábola Editorial, 2008. 
, William. The social stratification of English in New York City.

Washington, DC. Center of Applied Linguistics, 1966.

LAMBERT, Wallace. E. A social psychology of bilingualism. Journal of social Issues, 23, 91-109, 1967.

LAMBERT, William W.; LAMBERT, Wallace E. Psicologia social. 4 ed. revista e ampliada. Trad. Dante Moreira Leitel. Rio de Janeiro: Zahar, 1975.

LAMBERT, W. HODGSON, R., GARDNER, R. and FILLENBAUM, $S$. Evaluational reactions to spoken languages. Journal of Abnormal and Social Psychology 60, 44-51. 1960.

MARTINS, Germano Ferreira. A alternância Tu/Você/Senhor no município de Tefé - Estado do Amazonas. 110 f. 2010. Dissertação (Mestrado e m Linguística). Instituto de Letras / Universidade de Brasília, 2010.

MIRANDA, Antonio Luiz Alencar. Atitudes Linguísticas dos falantes no Maranhão. Projeto de pesquisa aprovado pela FAPEMA e UEMA em 2016, Caxias: UEMA, 2016.

Crenças, atitudes e usos variáveis da concordância verbal com o pronome tu. Rio de Janeiro: 2014. 157 f. Tese (Doutorado em Linguística), Faculdade de Letras, Universidade Federal do Rio de Janeiro, 2014.

RICHARDS L. C.; SCHMIDT, R. Longman dictionary of language teaching \& applied linguistics. Edinburg Gate: Pearson Education Limited, 2002.

SCHNEIDER, M. N. As atitudes e concepções linguísticas e sua relação com as práticas sociais de professores em comunidades bilíngues alemãoportuguês do Rio Grande do Sul. 286 f. Tese (Doutorado em Letras) - Instituto de Letras, UFRGS, PORTO Alegre, 2007.

Data da Submissão: 01/05/2018

Data da Aprovação: 26/07/2018 